\title{
EPR and Optical Spectroscopy of Iron Doped Mixed Alkali Cadmium Phosphate Glasses
}

\author{
G. Giridhar ${ }^{a, *}$, D. Punyaseshudu ${ }^{b}$, M.V.V.K. Srinivas Prasad ${ }^{c}$, M. Venkateswarlu $^{c}$ \\ AND G. SRINIVAS ${ }^{c, d}$
}

${ }^{a}$ Department of Nanotechnology, Acharya Nagarjuna University, Nagarjunanagar - 522510, Guntur, India

${ }^{b}$ Department of Physics, Rayalaseema University, Kurnool, India

${ }^{c}$ Department of Physics, KL University, Vijayawada, India

${ }^{d}$ Department of Physics, NRI Institute of Technology, Agiripalli, Krishna(Dt.), India

(Received July 20, 2012; in final form March 1, 2013)

\begin{abstract}
Iron doped mixed alkali cadmium phosphate ( $\mathrm{LiNaCdP}$ ) glasses of the following chemical composition $x \mathrm{Li}_{2} \mathrm{O}+$ $(20-x) \mathrm{Na}_{2} \mathrm{O}+20 \mathrm{CdO}+59.5 \mathrm{P}_{2} \mathrm{O}_{5}+0.5 \mathrm{Fe}_{2} \mathrm{O}_{3}(5<x<15)$ were prepared by melt quenching technique to study the mixed alkali effect. To manifest the mixed alkali effect, electron paramagnetic resonance and optical absorption studies were carried out at room temperature for these phosphate glasses. The physical and optical properties of these glasses have been evaluated. The results accomplished for the present glass system point out the presence of mixed alkali effect for $x=10$.
\end{abstract}

DOI: $10.12693 /$ APhysPolA.123.761

PACS: 71.55.Jv, 61.43.Fs, 76.30.-v, 78.20.-e

\section{Introduction}

In oxide glasses mixing of two different alkali contents results in mixed alkali effect $[1,2]$. When the concentrations of the two alkali cations are mottled by keeping total fixed concentration of alkalis, a remarkable expedition from linearity was observed in electrical conductivity, viscosity, thermal properties and chemical durability. This nonlinear behavior in glass system as a function of composition is very different from a single modifier oxide glass system. Many physical properties deliberate in mixed-alkali systems show initial nonlinear growth and subsequent reversal in trends, leading to maxima or minima as a function of modifier fraction [1]. Due to the hygroscopic nature and precariousness of $\mathrm{P}_{2} \mathrm{O}_{5}$ at elevated temperatures [3] the studies concerned with structure and properties of the phosphate glasses are fairly limited. Varying the chemical composition, leads to a change in the local environment around the transition metal (TM) ion incorporated into the vitreous network, resulting in local ligand field inhomogeneities.

EPR and optical absorption studies of TM ions in glasses helps us to predict the energy levels involved in the transitions and also to know the chemical and structural environments around the TM ion. Cadmium phosphate based glasses have been used as matrices for the growth of cadmium selenide quantum dots. A considerable work [4-6] had been carried out on spectroscopic investigations of TM doped phosphate glasses in our laboratory. Recently, EPR and optical studies on

*corresponding author; e-mail: giridhar_nath@rediffmail.com cadmium borate glasses for mixed alkali effect was observed by Padmaja and Kistaiah [7]. In addition, several authors have reported mixed alkali effect (MAE) in borate glasses by theoretical and experimental investigations [8, 9]. Though, no reports are known for MAE in cadmium phosphate glasses. In this regard iron is chosen as a probe to investigate such phenomenon through spectroscopic methods for the present alkali cadmium phosphate glasses. Iron ions exist in different valence states with different local symmetries in the glass matrices, for example, as $\mathrm{Fe}^{3+}$ with both tetrahedral and octahedral coordination, and/or as $\mathrm{Fe}^{2+}$ with octahedral coordination [10]. Both $\mathrm{Fe}^{3+}$ and $\mathrm{Fe}^{2+}$ ions are well-known paramagnetic ions, but only $\mathrm{Fe}^{3+}\left(3 d^{5},{ }^{6} S_{5 / 2}\right)$ shows EPR absorptions at room temperature [10-13]. Influence of iron ions on the structural and magnetic properties [14], electrical and spectroscopic properties [15] in various phosphate glasses, silicate glasses [16] and borate glasses reveals the importance of iron ions in different valence states for different glass networks for different solid state electrochemical devices [17, 18] and electrochemical, electronic and electro-optic devices [19, 20].

The aim of the present study was to investigate mixed alkali effect by X-ray diffraction, optical absorption and electron paramagnetic resonance measurements the lithium sodium cadmium phosphate glasses containing $\mathrm{Fe}_{2} \mathrm{O}_{3}$ in order to establish the structural changes induced by iron oxide addition and to obtain information concerning microscopic structure of these glasses.

\section{Experimental}

Glasses of the system $x \mathrm{Li}_{2} \mathrm{O}+(20-x) \mathrm{Na}_{2} \mathrm{O}+$ $20 \mathrm{CdO}+59.5 \mathrm{P}_{2} \mathrm{O}_{5}+0.5 \mathrm{Fe}_{2} \mathrm{O}_{3}(5<x<15)$ were prepared using chemicals of analar grade $(99.9 \%)$. The prop- 
erly weighed chemicals were crushed in agate mortar in order to form a homogeneous mixture. The mixture was first sintered in porcelain crucible in an electric furnace at a temperature of $700 \mathrm{~K}$ and then melted at $1250 \mathrm{~K}$ for $1.5 \mathrm{~h}$. The melt was poured on a pre heated brass plate and annealed at $550 \mathrm{~K}$ for $3 \mathrm{~h}$ in order to remove the thermal strain. The samples were labeled as LiNaCdP1 $(x=5), \operatorname{LiNaCdP} 2(x=10)$ and $\operatorname{LiNaCdP} 3(x=15)$. The samples were confirmed to be amorphous in nature by XRD studies. The XRD spectrum was recorded on PHILIPS XPERT PRO X-ray diffraction system. EPR spectrum was recorded at room temperature on JES-FA series X band EPR spectrometer with $100 \mathrm{kHz}$ field modulations. The optical absorption spectra of the prepared samples were recorded at room temperature using JASCO (V-550) spectrophotometer in UV-VIS region.

Physical properties of $\mathrm{Fe}^{3+}$ doped LiNaCdP glasses.

TABLE I

\begin{tabular}{c|c|c|c}
\hline \hline Physical property & LiNaCdP1 & LiNaCdP2 & LiNaCdP3 \\
\hline Refractive index $\left(n_{\mathrm{d}}\right)$ at $589.3 \mathrm{~nm}$ & 1.54 & 1.53 & 1.519 \\
density, $d\left[\mathrm{~g} / \mathrm{cm}^{3}\right]$ & 3.46 & 3.45 & 3.44 \\
average molecular weight $M[\mathrm{~g}]$ & 121.72 & 120.12 & 118.5 \\
$\mathrm{Fe}^{3+}$ ion concentration & 1.712 & 1.729 & 1.748 \\
$N\left[\times 10^{22}\right.$ ions $\left./ \mathrm{cm}^{3}\right]$ & 6.700 & 6.631 & 6.561 \\
mean atomic volume $\left[\mathrm{g} / \mathrm{cm}^{3} /\right.$ atom] & 1.371 & 1.340 & 1.307 \\
optical dielectric constant $[P \partial t / \partial p]$ & 2.371 & 2.340 & 2.307 \\
dielectric constant $(\varepsilon)$ & 4.519 & 4.388 & 4.245 \\
reflection loss $(R)[\%]$ & 11.03 & 10.75 & 10.45 \\
molar reflection $\left(R_{\mathrm{m}}\right)\left[\mathrm{cm}^{-3}\right]$ & 1.563 & 1.558 & 1.552 \\
polaron radius $r_{\mathrm{p}}[\AA]$ & 3.879 & 3.866 & 3.852 \\
interionic distance $r_{\mathrm{i}}[\AA]$ & 4.374 & 4.262 & 4.144 \\
molecular electronic polarizability & & & \\
$\alpha\left[\times 10^{-24} \mathrm{~cm}^{3}\right]$ & 8.180 & 8.236 & 8.295 \\
field strength $F\left[\times 10^{15} \mathrm{~cm}^{-2}\right]$ & &
\end{tabular}

The densities for the prepared glasses were measured by using Archimedes principle, with xylene as an immersion liquid. The refractive index of these glasses have been measured at $\lambda=589.3 \mathrm{~nm}$ on a Abbé refractometer with the monobromonapthalane as a contact layer between the sample and prism of a refractometer by using sodium vapor lamp as the source. The other physical properties such as Fe ion concentration $(N)$, dielectric constant $(\varepsilon)$, polaron radius $\left(r_{\mathrm{p}}\right)$, inter ionic distance $\left(r_{\mathrm{i}}\right)$, field strength $(F)$, reflection loss from the glass surface $(R)$, molar refractivity $\left(R_{\mathrm{M}}\right)$ have been evaluated by using the standard formulae [21-25]. Table I illustrates the variation of physical properties of the glasses studied in the present work. The optical dielectric constant $P \partial t / \partial p$ was calculated from the measured refractive index at $589.3 \mathrm{~nm}$ using the formula [26]:

$$
P \partial t / \partial p=\varepsilon-1=n_{\mathrm{d}}^{2}-1,
$$

where $\varepsilon$ is the dielectric constant. The molecular electronic polarizability factor $\left(\alpha_{\mathrm{e}}\right)$ was determined using the formula [27]:

$$
\alpha_{\mathrm{e}}=\frac{1}{4 \pi N / 3}\left(\frac{n_{\mathrm{d}}^{2}-1}{n_{\mathrm{d}}^{2}+2}\right),
$$

where $n_{\mathrm{d}}$ is the refractive index at $589.3 \mathrm{~nm}$ and $N$ is the $\mathrm{Fe}^{3+}$ ion concentration. From the average molecu- lar weight of the glass, the densities and total number of ions, the mean atomic volume (in $\mathrm{g} / \mathrm{cm}^{3} /$ atom) can be obtained.

\section{Results and discussions}

The amorphous nature of the prepared glass (LiNaCdP) was confirmed by recording powder X-ray diffraction spectra for all the glasses at room temperature. The absence of the Bragg peaks confirms the amorphous nature of the prepared glasses and is shown in Fig. 1. The evaluated physical properties for the present glass system are shown in Table I.

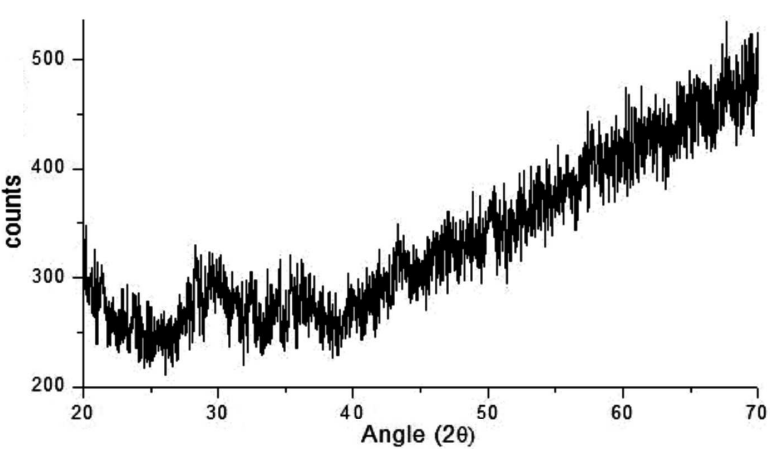

Fig. 1. X-ray difraction pattern of LiNaCdP glass $\left(\mathrm{Cu} K_{\alpha}=1.54 \AA\right)$.

Figure 2 shows X band EPR spectra of 0.5 mol.\% of $\mathrm{Fe}^{3+}$ ions in lithium sodium cadmium phosphate glasses $(\mathrm{LiNaCdP})$ recorded at room temperature. The EPR spectra of all the glass samples reveal two intense resonance signals which are characteristic of $\mathrm{Fe}^{3+}$ ion. The two intense resonance signals occurred at $g \approx 4.3$ and at $g \approx 2.0$ i.e. at low and high magnetic fields, respectively. The $g$ values obtained for all the glasses are given in Table II.

TABLE II

The observed $g$ values for different glasses.

\begin{tabular}{c|c|c}
\hline \hline Glass sample & \multicolumn{2}{|c}{$g$ values } \\
\hline LiNaCdP1 & 4.32 & 1.9919 \\
LiNaCdP2 & 4.32 & 1.9881 \\
LiNaCdP3 & 4.32 & 1.9894
\end{tabular}

In general, the absorption at $g \approx 4.2 \pm 0.1$ is due to isolated $\mathrm{Fe}^{3+}$ ions located in sites of distorted octahedral symmetry (rhombic or tetragonal) subjected to strong crystal field effects and $g \approx 2$ line may be attributed either to $\mathrm{Fe}^{3+}$ species interacting by dipole-dipole interaction in sites of less distorted octahedral (tetrahedral) field or to superexchange coupled pairs, respectively [28-30]. $\mathrm{Fe}^{3+}$ ions belong to $d^{5}$ configuration with ${ }^{6} S_{5 / 2}$ as the ground state in the free ion and there is no spin-orbit interaction [31]. The " $g$ " value is expected to lie very near to the 


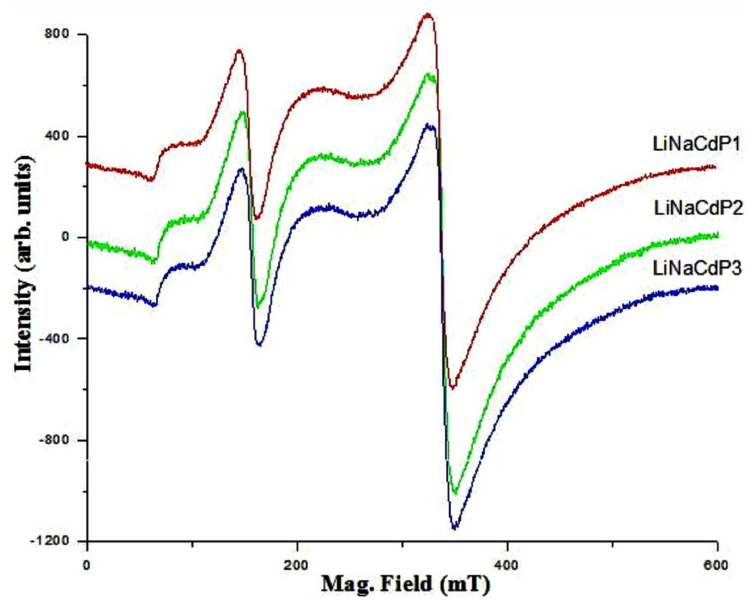

Fig. 2. EPR spectra of mixed alkali cadmium phosphate glasses at X-band frequency.

free-ion value of 2.0023. The higher $g$ values at $4.2 \pm 0.1$ occur due to the presence of certain symmetry elements. That is the resonance line is often associated with the low symmetry rhombic sites of either tetrahedral or octahedral coordination. In a crystal field environment, the ${ }^{6} S$ ground state splits into three Kramers doublets $| \pm 1 / 2\rangle,| \pm 3 / 2\rangle$ and $| \pm 5 / 2\rangle$. The resonance signal at $g \approx 4.2 \pm 0.1$ results from the middle Kramers doublet $| \pm 3 / 2\rangle$ [32]. The observed resonances at $g \approx 4.2 \pm 0.1$ have been attributed to the isolated $\mathrm{Fe}^{3+}$ ions in rhombic symmetry sites $[12,33-35]$. The $g \approx 2.0$ resonance may be attributed to either $\mathrm{Fe}^{3+}$ ions interacting by dipoledipole interaction in sites of less distorted octahedral field or to their super exchange interactions within the pairs or iron ions $[33,35,36]$. These $g$ values observed in the present work for all the samples indicate that the iron ions are in trivalent state and the site symmetry is distorted octahedral.

In the present LiNaCdP glasses, because of the ionic radii of iron ions [37], there is no such higher variation in $g$ values with concentration variation of alkali content. From Table II it is also observed that when the lithium concentration increases the iron-ligand bonding covalency nature decreases to some extent. In particular for $x=10$ sample, the covalence nature slightly decreases when compared to other glasses shows mixed alkali effect. The optical absorption spectrum of 0.5 mol. $\%$ of $\mathrm{Fe}_{2} \mathrm{O}_{3}$ in lithium sodium cadmium phosphate glass samples is shown in Fig. 3.

Electronic configuration of $\mathrm{Fe}^{3+}\left(d^{5}\right)$ gives rise to free ion terms ${ }^{6} S,{ }^{4} P,{ }^{4} \mathrm{~F},{ }^{4} G$, in addition to a number of doublet states of which ${ }^{6} S$ occupies the ground state. ${ }^{6} S$ and ${ }^{4} P$ terms transform as ${ }^{6} A_{1 \mathrm{~g}}$ and ${ }^{4} T_{1 \mathrm{~g}}$, respectively, in crystal fields. ${ }^{4} D$ and ${ }^{4} G$ splits into ${ }^{4} E_{\mathrm{g}}+{ }^{4} T_{2 \mathrm{~g}}$ and ${ }^{4} A_{1 \mathrm{~g}}+{ }^{4} E_{\mathrm{g}}+{ }^{4} T_{1 \mathrm{~g}}+{ }^{4} T_{2 \mathrm{~g}}$, respectively. The spectra exhibits two bands centered at $\approx 458 \mathrm{~nm}\left(21828 \mathrm{~cm}^{-1}\right)$, and $\approx 410 \mathrm{~nm}\left(24407 \mathrm{~cm}^{-1}\right)$. These bands have been assigned to the transitions ${ }^{6} A_{1 \mathrm{~g}}(S) \rightarrow{ }^{4} T_{2 \mathrm{~g}}(G)$ and

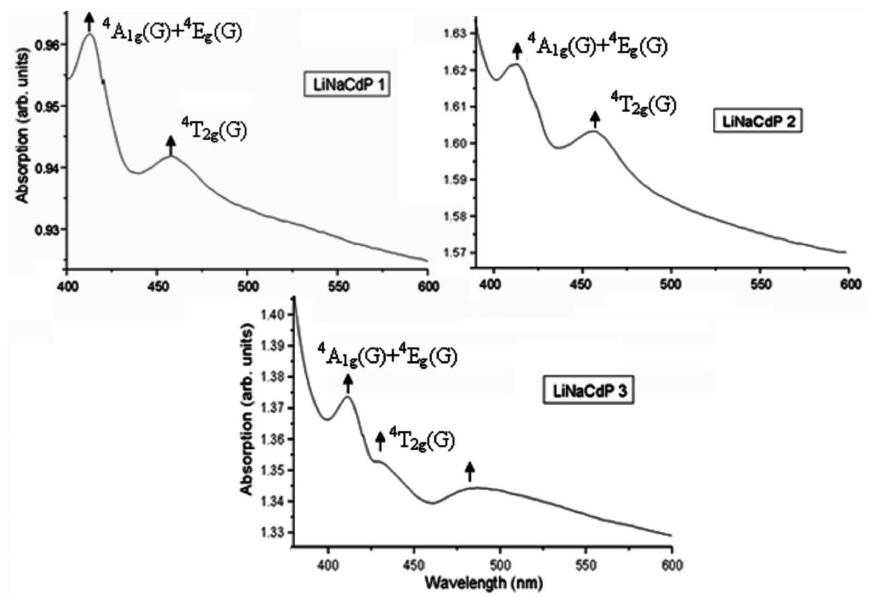

Fig. 3. Optical absorption spectra of mixed alkali cadmium phosphate glasses.

${ }^{6} A_{1 \mathrm{~g}}(S) \rightarrow{ }^{4} A_{1 \mathrm{~g}}(G)+{ }^{4} E_{\mathrm{g}}(G)$, respectively. The band positions are representing the distorted octahedral symmetry of trivalent iron ions [38-40]. The energy matrices inclusive of the Trees correction [41] are formed by adding appropriate Trees correction to the energy matrices of $d^{5}$ configuration in a cubic field given by Tanabe and Sugano [42]. The observed and calculated band positions along with their assignments are given in Table III.

Band assignments for the optical absorption spectra.

TABLE III

\begin{tabular}{c|c|c|c|c|c|c}
\hline \hline \multirow{2}{*}{ Transition } & \multicolumn{2}{|c|}{ LiNaCdP1 } & \multicolumn{2}{c|}{ LiNaCdP2 } & \multicolumn{2}{c}{ LiNaCdP3 } \\
\cline { 2 - 7 } & observed & calculated & observed & calculated & observed & calculated \\
\hline${ }^{4} T_{2 \mathrm{~g}}(G)$ & 21828 & 21819 & 21828 & 21797 & 20741 & 21964 \\
${ }^{4} A_{1 \mathrm{~g}}(G)+{ }^{4} E_{\mathrm{g}}(G)$ & 24235 & 24247 & 24401 & 24407 & 24294 & 24296
\end{tabular}

The inclusion of the Trees correction " $\alpha$ " equal to $90 \mathrm{~cm}^{-1}$ is necessary in order to obtain a good fit between the observed and calculated values. By digitizing the energy matrices inclusive of the Trees correction $(\alpha)$, the 
crystal field parameter $D_{q}$ and the Racah inter-electronic repulsion parameters $B$ and $C$ have been evaluated and tabulated in Table IV.

\section{TABLE IV}

Crystal field parameter and Racah's parameters.

\begin{tabular}{c|c|c|c}
\hline \hline Sample & $D_{q}$ & $B$ & $C$ \\
\hline LiNaCdP1 & 830 & 848 & 2800 \\
LiNaCdP2 & 865 & 865 & 2800 \\
LiNaCdP3 & 815 & 852 & 2800
\end{tabular}

The value of inter-electronic repulsion parameter $B$ obtained in the present work for LiNaCdP2 is large compared to others. But it is far away from the free ion value $\left(1300 \mathrm{~cm}^{-1}\right)$ [43]. Due to equal concentration of alkali content, the bond nature of $\mathrm{LiNaCdP} 2$ sample is less covalent than others. Here optical absorption spectra for increase of lithium content $(x=15)$, the transition to ${ }^{4} T_{2 \mathrm{~g}}(G)$ state splits into two levels, may be due to the lowering of symmetry by occupation of lithium sites by iron ions.

\section{Conclusions}

The EPR spectra of $\mathrm{Fe}^{3+}$ ion doped LiNaCdP glasses exhibit two resonance signals at $g \approx 4.3$ and 2.0 . The resonances at $g \approx 4.3$ have been attributed to $\mathrm{Fe}^{3+}$ ions in rhombic symmetry sites. The resonance signal at $g \approx$ 2.0 is due to two or more $\mathrm{Fe}^{3+}$ ions coupled together with dipolar interaction.

The optical absorption spectrum of $\mathrm{Fe}^{3+}$ ion doped LiNaCdP glasses exhibits two bands characteristic of $\mathrm{Fe}^{3+}$ ions in an octahedral symmetry. The crystal field parameter $D_{q}$ and Racah's inter-electronic repulsion parameters $B$ and $C$ have been evaluated. It is observed that the obtained inter-electronic repulsion parameter $B$ varies with the variation of alkali content and shows mixed alkali effect at $x=10$ (LiNaCdP2 glass). Thus it indicates that the nature of bonding in the present glass system is strictly covalent. Additionally, the lowering of symmetry is also observed in optical absorption spectra at higher concentration of lithium with increased hygroscopic nature. From the above studies, it is concluded that when the lithium concentration increases the iron-ligand bonding covalency nature decreases to some extent, for instance for $x=10$ sample, the covalence nature slightly decreases when compared to other glasses and shows mixed alkali effect.

\section{References}

[1] J.O. Isard, J. Non-Cryst. Solids 1, 235 (1969).

[2] D.E. Day, J. Non-Cryst. Solids 21, 343 (1976).

[3] J.W. Wiench, B. Tischendorf, J.U. Otaigbe, M. Pruski, J. Mol. Struct. 602, 145 (2002).
[4] G. Giridhar, M. Rangacharyulu, R.V.S.S.N. Ravi Kumar, P. Sambasiva Rao, Opt. Electron. Adv. Mater. Rapid Commun. 2, 433 (2008).

[5] G. Giridhar, M. Rangacharyulu, R.V.S.S.N. Ravi Kumar, P. Sambasiva Rao, J. Mater. Sci. Technol. 25, 531 (2009).

[6] G. Giridhar, M. Rangacharyulu, R.V.S.S.N. Ravi Kumar, P. Sambasiva Rao, IOP Conf. Series: Mater. Sci. Eng. 2, 012058 (2009).

[7] G. Padmaja, P. Kistaiah, Solid State Sci. 12, 2015 (2010).

[8] R.P. Sreekanth Chakradhar, B. Yasoda, J.L. Rao, N.O. Gopal, J. Non-Cryst. Solids 353, 2355 (2007).

[9] R.P. Sreekanth Chakradhar, B. Yasoda, J. Lakshmana Rao, N.O. Gopal, J. Non-Cryst. Solids 352, 3864 (2006).

[10] R.K. Singh, G.P. Kothiyal, A. Srinivasan, J. NonCryst. Solids 354, 3166 (2008).

[11] D. Loveridge, S. Parke, Phys. Chem. Glasses 9, 73 (1968).

[12] D.L. Griscom, J. Non-Cryst. Solids 40, 211 (1980).

[13] I. Ardelean, P. Pascuta, Int. J. Mod. Phys. B 18, 1525 (2004)

[14] P. Pascuta, G. Borodi, A. Popa, V. Dan, E. Culea, Mater. Chem. Phys. 123, 767 (2010).

[15] P. Raghava Rao, L. Pavić, A. Moguš-Milanković V. Ravikumar, I.V. Kityk, N. Veeraiah, J. NonCryst. Solids 358, 3255 (2012).

[16] N.Ch. Ramesh Babu, M.A. Valente, N. Narasimha Rao, M.P.F. Graça, G. Naga Raju, M. Piasecki, I.V. Kityk, N. Veeraiah, J. Non-Cryst. Solids 358 , 3175 (2012)

[17] X. Yu, J.B. Bates, G.E. Jellison Jr., F.X. Hart, J. Electrochem. Soc. 144, 524 (1997).

[18] F. Scholz, J. Solid State Electrochem. 15, 5 (2011).

[19] M. Jamnický, P. Znasic, D. Tunega, M.D. Ingram, J. Non-Cryst. Solids 185, 151 (1995).

[20] N.J. Cherepy, D.B. Liston, J.A. Lovejoy, H. Deng, J.Z. Zhang, J. Phys. Chem. B 102, 770 (1998).

[21] A. Sankar, A. Das Gupta, B. Babsu, A. Paul, J. Mater. Sci. Lett. 4, 697 (1983).

[22] M.M. Ahmed, C.A. Hogarath, M.N. Khan, J. Mater. Sci. Lett. 19, 4040 (1984).

[23] Y. Ohisti, S. Mitachi, Y. Tanabe, Phys. Chem. Glasses 24, 135 (1983).

[24] B. Bendow, P.K. Banerjee, M.G. Drexhage, J. Lucas, J. Am. Ceram. Soc. 65, C92 (1985).

[25] J.E. Shelby, J. Ruller, Phys. Chem. Glasses 28, 262 (1987).

[26] J. Schroeder, J. Non-Cryst. Solids 40, 549 (1980).

[27] A. Kłonkowski, J. Non-Cryst. Solids 72, 117 (1985).

[28] I. Ardelean, M. Peteanu, S. Filip, V. Simon, G. Gyorffy, Solid State Commun. 102, 341 (1997).

[29] J. Lakshman Rao, A. Murali, E. Dhananjay Rao, J. Non-Cryst. Solids 202, 215 (1996).

[30] C. Hirayama, J.G. Castle Jr., M. Kuriyama, Phys. Chem. Glasses 9, 109 (1968).

[31] D. Loveridge, S. Parke, Phys. Chem. Glasses 12, 19 (1971). 
[32] J. Kliava, Phys. Status Solidi B 134, 411 (1986).

[33] T. Castner Jr., G.S. Newell, W.C. Holton, C.P. Slichter, J. Chem. Phys. 32, 668 (1960).

[34] E. Burzo, I. Ursu, D. Ungur, I. Ardelean, Mater. Res. Bull. 15, 1273 (1980).

[35] I. Ardelean, P. Pascuta, L.V. Giurgiu, Int. J. Mod. Phys. B 17, 3049 (2003).

[36] E. Burzo, I. Ardelean, I. Ursu, J. Mater. Sci. 15, 581 (1980).

[37] R.P. Sreekanth Chakradhar, G. Sivaramaiah, J. Lakshmana Rao, N.O. Gopal, Spectrochim. Acta A 62 51 (2005).

[38] T. Bates, in: Modern Aspects of the Vitreous State, Ed. J.D. Mackenzie, Vol. 2, Butterworths, London 1962, p. 242.
[39] T. Abrita, F.S. Barros, J. Lumin. 40, 187 (1988).

[40] M.L. Baesso, E.C. da Silva, F.C.G. Gandra, H. Vargas, P.P. de Areu Filho, F. Galembeck, Phys. Chem. Glasses 31, 123 (1990).

[41] R.E. Trees, Phys. Rev. 83, 756 (1951).

[42] Y. Tanabe, S. Sugano, J. Phys. Soc. Jpn. 9, 753 (1954).

[43] B.N. Figgis, Introduction to Ligand Fields, Wiley Eastern, New Delhi 1976, p. 23. 